\title{
Accelerating our response: Government of Canada five-year action plan on sexually transmitted and blood-borne infections
}

\author{
C Jackson ${ }^{1}$, G Tremblay ${ }^{1}$ on behalf of the Government of Canada STBBI Action Plan Steering \\ Committee* $^{*}$
}

\begin{abstract}
Sexually transmitted and blood-borne infections (STBBI)—which include HIV, hepatitis B and $C$, chlamydia, gonorrhea, syphilis and human papillomavirus-remain significant public health issues both nationally and globally. In 2018, a Pan-Canadian STBBI Framework for Action (the Framework) was released by federal, provincial and territorial governments to provide an overarching and comprehensive approach to addressing STBBI for all those involved. This includes all levels of government, First Nations, Inuit and Métis communities and leadership, frontline service providers, clinicians, public health practitioners, non-governmental organizations and researchers. The Framework includes strategic goals, guiding principles and pillars for action to address STBBI in Canada. In response, the Government of Canada released its own action plan in July 2019: Accelerating Our Response - Government of Canada Five-Year Action Plan on Sexually Transmitted and Blood-Borne Infections (the Action Plan). This document identifies seven priority areas for federal action on STBBI over the next five years: 1) moving toward truth and reconciliation with First Nations, Inuit and Métis Peoples; 2) stigma and discrimination; 3) community innovation-putting a priority on prevention; 4) reaching the undiagnosed-increasing access to STBBI testing; 5) providing prevention, treatment and care to populations that receive health services or coverage of health care benefits from the federal government; 6) leveraging existing knowledge and targeting future research; and 7) measuring impact-monitoring and reporting on trends and results. The Government of Canada is currently working with provincial and territorial governments, First Nations, Inuit and Métis partners, and other stakeholders to develop STBBI indicators and targets for the Canadian context that are appropriate, feasible and measurable against the shared strategic goals of the Framework and the Action Plan. In addition, the Government of Canada has also committed to reporting annually on its progress in implementing the priority areas laid out in the Action Plan.
\end{abstract}

This work is licensed under a Creative Commons Attribution 4.0 International License.

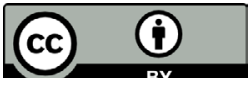

Affiliation

${ }^{1}$ Centre for Communicable Diseases and Infection Control, Public Health Agency of Canada, Ottawa, ON

\section{*Correspondence:}

ccdic-clmti@phac-aspc.gc.ca

Suggested citation: Jackson C, Tremblay G on behalf of the Government of Canada STBBI Action Plan Steering Committee. Accelerating our Response: Government of Canada Five-Year Action Plan on Sexually Transmitted and Blood-Borne Infections. Can Comm Dis Rep 2019;45(12):323-6.

https://doi.org/10.14745/ccdr.v45i12a04

Keywords: STBBI, action plan, Framework, Canada

\section{Introduction}

Sexually transmitted and blood-borne infections (STBBI)—which include HIV, hepatitis B and C, chlamydia, gonorrhea, syphilis and human papillomavirus_-remain significant public health concerns in Canada. Rates of sexually transmitted infections in Canada rose dramatically between 2008 and 2017: chlamydia rose by $39 \%$, gonorrhea by $109 \%$ and syphilis by $167 \%$ (1). Over the past several years, a number of jurisdictions have declared syphilis outbreaks, and cases of congenital syphilis have also increased (2-4). Although HIV-related deaths and rates of reported hepatitis $C$ cases have decreased substantially since the 1990s, new infections continue to occur $(5,6)$. Globally, there is momentum to eliminate STBBI as a public health concern, and Canada has endorsed the World Health Organization's global targets for HIV, viral hepatitis and sexually transmitted infections. These infections share common transmission routes and risk factors, and the populations most affected or likely to be exposed often overlap.

Improving the prevention, testing, treatment and care of STBBI is complex and involves a number of actors, including all levels 
of government, First Nations, Inuit and Métis communities and leadership (Text box), frontline service providers, clinicians, public health practitioners, non-governmental organizations and researchers. In 2018, the Public Health Agency of Canada released a Pan-Canadian STBBI Framework for Action (hereafter called the Framework) (7), which was endorsed by federal, provincial and territorial ministers of health. The Framework provides an overarching and comprehensive approach to addressing STBBI for all those involved. It identifies strategic goals, guiding principles and pillars for action spanning the STBBI continuum of care and highlights the role of enabling environments-social, cultural, physical, structural and legal conditions-that support the prevention of STBBI transmission and promote access to services. The Framework was summarized in a previous Canada Communicable Disease Report article (8).

Text box: Federal departments involved in the Government of Canada Five-Year Action Plan on Sexually Transmitted and Blood-Borne Infections:

- Public Health Agency of Canada

- Canadian Institutes of Health Research

- Correctional Service Canada

- Department of Justice

- Department of National Defence

- Department of Women and Gender Equality

- Health Canada

- Immigration, Refugees and Citizenship Canada

- Indigenous Services Canada

- LGBTQ2 Secretariat of the Privy Council Office

In July 2019, the Government of Canada (GoC) released its own plan outlining key federal priorities to reduce the public health impacts of STBBI in Canada and advance the work of the Framework from 2019 to 2024. This plan, entitled Accelerating Our Response: Government of Canada Five-Year Action Plan on Sexually Transmitted and Blood-Borne Infections (hereafter called the Action Plan) (9) takes a whole-of-government approach and involves ten federal departments whose mandates and activities address aspects of STBBI and/or who are responsible for providing prevention, treatment and care or coverage of health care benefits to specific populations.

This plan shares the strategic goals of the Framework. These goals are to 1) reduce the incidence of STBBI in Canada,

2) improve access to testing, treatment, care and support and

3) reduce the stigma and discrimination that create vulnerabilities to STBBI. The following article summarizes the Action Plan and briefly describes its seven priority areas.

\section{Renewing the federal response to STBBI: Overview of the Action Plan}

The Action Plan includes seven priority areas.
1. Moving toward truth and reconciliation with First Nations, Inuit and Métis Peoples

The Action Plan's commitment to moving toward truth and reconciliation with First Nations, Inuit and Métis Peoples reflects the broader $\mathrm{GoC}$ commitment to reconciliation. The $\mathrm{GoC}$ will take an approach to STBBI policy, programs and services that address the priorities identified by First Nations, Inuit and Métis communities. Under this priority area, the GoC will support First Nations, Inuit and Métis Peoples' priorities in relation to STBBI, improve availability and accessibility of community level data on STBBI outcomes, and invest in culturally safe and responsive initiatives for STBBI prevention, education, awareness, and ongoing care and support.

\section{Stigma and discrimination}

Stigma and discrimination remain key obstacles to effective STBBI prevention, care, treatment and support. Disproportionate rates of STBBI affect populations that face various types of stigma and discrimination, including sexism, racism and homophobia. Stigma and discrimination also impede access to appropriate prevention, care, treatment and support services for STBBI. The GoC will promote the important message of undetectable $=$ untransmittable $(U=U)$, which is based on the substantial body of scientific evidence indicating that, for people living with HIV who have achieved a sustained undetectable viral load, there is effectively no risk of sexual transmission. Under this priority area, the $\mathrm{GoC}$ will also work to:

- Address stigma and discrimination (including racism and sexism), gender-based violence, transphobia, biphobia and homophobia

- Equip professionals with skills to provide culturally safe and responsive services in safe environments

- Reduce the over-criminalization of HIV non-disclosure in Canada

\section{Community innovation-putting a priority on prevention}

The GoC will continue its long-standing support for community-based organizations that work to prevent STBBI with programs and interventions tailored to the particular contexts and priorities of specific communities. This includes federal grants and contributions programs including the Harm Reduction Fund (10) and the HIV and Hepatitis C Community Action Fund (11). Under this priority area, the GoC will support frontline, community-based projects to prevent new and recurring infections, reach the undiagnosed and link them to testing, treatment and care, and support efforts to bring high impact interventions, such as HIV preexposure prophylaxis, to scale so more people can benefit from them.

\section{Reaching the undiagnosed-increasing access to STBB testing}

Testing for STBBI enables people to access care, treatment and support, and can ultimately reduce onward transmission of infections. However, current approaches to STBBI testing are not reaching everyone who could benefit. For this reason, under this priority area, the $\mathrm{GoC}$ will prioritize efforts to increase access to 
culturally-safe and responsive testing models and expand the range of testing options available to people in Canada, including point-of-care testing, self-testing and the use of dried blood spot technology.

5. Prevention, treatment and care for populations that receive health services or coverage of health care benefits from the federal government

The GoC funds and provides health services or coverage of health care benefits for a number of specific populations, including members of the Canadian Armed Forces, certain immigrant populations, incarcerated individuals in federal correctional facilities and eligible First Nations and Inuit. Under this priority area, the $\mathrm{GoC}$ will ensure that eligible individuals receive effective and culturally safe and responsive prevention, including harm reduction, care and treatment services, and facilitate linkage to care for those transitioning from federal to provincial and territorial health systems.

\section{Leveraging existing knowledge and targeting future research}

Scientific research continues to advance and improve knowledge about STBBI, the conditions that promote vulnerability to infection, the development of new prevention and testing modalities and treatments and knowledge about the physical, mental and social impacts of living with chronic infection. Under this priority area, the $\mathrm{GoC}$ will invest in the following areas: research on basic, translational and clinical research; research supporting STBBI prevention, testing and diagnosis, treatment and care; and support for the development of First Nations, Inuit and Métis health research capacity.

\section{Measuring impact-monitoring and reporting on trends and results}

Global targets for HIV, hepatitis and sexually transmitted infections are part of the momentum driving Canada's efforts to reduce the health impacts of STBBI. However, global targets are not sufficient to unify efforts, drive change and measure Canada's progress. Under this priority area, the GoC will lead a process to develop indicators and targets for STBBI that are appropriate for the Canadian context. It will also prioritize efforts to strengthen Canada's STBBI surveillance system to ensure that the GoC has the data that is needed to focus efforts and monitor trends and changes over time. In addition, the $\mathrm{GoC}$ has committed to reporting on the results from this Action Plan on an annual basis.

\section{Conclusion and next steps}

The Action Plan outlines the seven priority areas for federal efforts to implement the Framework and support Canada's contribution to meeting the global targets for HIV, hepatitis and sexually transmitted infections by 2030 (Table 1). The GoC is currently working with provincial and territorial governments, First Nations, Inuit and Métis partners, and other stakeholders to develop STBBI indicators and targets within the Canadian context that are appropriate, feasible and measurable. This work will include a community consultation process over the coming months. The GoC has also committed to reporting annually on its progress in implementing the priority areas laid out in the Action Plan. Full implementation of the Framework, however, will require the ongoing and unified efforts of governments, stakeholders and affected communities to ensure that culturally-safe and responsive STBBI prevention, testing, care, treatment and support are available to those who need it.

\section{Table 1: Global Targets for Sexually Transmitted and Blood-Borne Infections (STBBI)}

\begin{tabular}{|c|c|c|}
\hline STBBI & $\begin{array}{l}\text { Target } \\
\text { year }\end{array}$ & Global targets \\
\hline \multirow[t]{2}{*}{ HIV } & 2020 & $\begin{array}{l}\text { - } 90 \% \text { of people living with HIV know their } \\
\text { status } \\
\text { - } 90 \% \text { of people living with HIV who know } \\
\text { their status are receiving treatment } \\
\text { - } 90 \% \text { of people on treatment have } \\
\text { suppressed viral loads } \\
\text { - Fewer than } 500,000 \text { new HIV infections } \\
\text { - Elimination of HIV-related discrimination }\end{array}$ \\
\hline & 2030 & $\begin{array}{l}\text { - Zero new HIV infections } \\
\text { - Zero AIDS-related deaths } \\
\text { - Zero discrimination }\end{array}$ \\
\hline \multirow[t]{2}{*}{ Hepatitis } & 2020 & $\begin{array}{l}\text { - } 30 \% \text { reduction in new cases of chronic viral } \\
\text { hepatitis B and C infections } \\
\text { - } 10 \% \text { reduction in hepatitis B and C deaths } \\
\text { - } 30 \% \text { of viral hepatitis B and C infections are } \\
\text { diagnosed } \\
\text { - Five million people receiving hepatitis } \\
\text { B treatment, and three million people } \\
\text { receiving hepatitis C treatment } \\
\text { - Achieve and maintain up-to-date } 90 \% \\
\text { coverage for vaccination of hepatitis B } \\
\text { vaccine (three doses) }\end{array}$ \\
\hline & 2030 & $\begin{array}{l}\text { - } 90 \% \text { reduction in new cases of chronic viral } \\
\text { hepatitis B and C infections } \\
\text { - } 65 \% \text { reduction in hepatitis B and C deaths } \\
\text { - } 90 \% \text { of viral hepatitis B and C infections are } \\
\text { diagnosed } \\
\text { - } 80 \% \text { of eligible people receiving hepatitis B } \\
\text { and C treatment }\end{array}$ \\
\hline $\begin{array}{l}\text { Sexually } \\
\text { transmitted } \\
\text { infections }\end{array}$ & 2030 & $\begin{array}{l}\text { - } 90 \% \text { reduction of syphilis incidence globally } \\
\text { - } 90 \% \text { reduction in gonorrhea incidence } \\
\text { globally } \\
\text { - } 50 \text { or fewer cases of congenital syphilis per } \\
100,000 \text { live births in } 80 \% \text { of countries } \\
\text { - } \quad \text { Sustain } 90 \% \text { national coverage and at } \\
\text { least } 80 \% \text { in every district (or equivalent } \\
\text { administrative unit) in countries with the } \\
\text { human papillomavirus vaccine in their } \\
\text { national immunization programme }\end{array}$ \\
\hline
\end{tabular}

The success of these efforts lies in partnerships. The GoC is committed to implementing the Truth and Reconciliation Commission's Calls to Action (12) and will continue to engage closely with First Nations, Inuit and Métis communities and leadership. The $\mathrm{GoC}$ is also committed to continuing to work with people with lived experience as programs and policies are developed. In addition, the GoC's collaborative work with provinces, territories and community-based organizations 
remains critical to achieving the shared strategic goals for STBBI. With the Action Plan, the federal government will continue to drive progress on HIV, viral hepatitis and sexually transmitted infections within the context of the Framework.

\section{Authors' statement}

CJ - Writing and editing

GT - Writing and editing

\section{Conflict of interest}

None.

\section{Acknowledgements}

The Public Health Agency of Canada would like to thank all those who contributed their time and expertise to the development of the Action Plan.

\section{References}

1. Public Health Agency of Canada. Report on Sexually Transmitted Infections in Canada, 2017. Ottawa (ON): PHAC; 2019.

2. Choudhri Y, Miller J, Sandhu J, Leon A, Aho J. Infectious and congenital syphilis in Canada, 2010-2015. Can Commun Dis Rep 2018;44(2):43-8. DOI PubMed

3. The Society of Obstetricians and Gynaecologists of Canada. SOGC Infectious Diseases Committee Statement on Syphilis. Ottawa (ON): SOGC; 2019. https://www.sogc.org/ en/content/featured-news/sogc-infectious-diseases-com mittee-statement-on-syphilis.aspx

4. Public Health Agency of Canada. Infectious syphilis in Canada, 2018. Can Commun Dis Rep 2019;45(11):302. https://www.canada.ca/en/public-health/services/ reports-publications/canada-communicable-disease-reportccdr/monthly-issue/2019-45/issue-11-november-7-2019/ article-5-infectious-syphilis-canada-2009-2018.html
5. Haddad N, Li JS, Totten S, McGuire M. HIV in Canadasurveillance Report, 2017. Can Commun Dis Rep 2018:44(12):348-56. DOl PubMed

6. Public Health Agency of Canada. Reported cases from 1924 to 2017 in Canada - Notifiable diseases on-line. Hepatitis C: Rate per 100,000 of reported cases over time in Canada, grouped by disease. Ottawa (ON): PHAC; modified 2019. (Accessed 2019-10-03). https://diseases.canada.ca/ notifiable/charts?c=pl\#d=173\&y=1985\%2C2016\&o=r

7. Public Health Agency of Canada. Reducing the Health Impact of Sexually Transmitted and Blood-Borne Infections in Canada by 2030: A Pan-Canadian STBBI Framework for Action. Ottawa (ON): PHAC; 2018 June. https://www.canada. ca/en/public-health/services/infectious-diseases/sexual-healt h-sexually-transmitted-infections/reports-publications/ sexually-transmitted-blood-borne-infections-actionframework.html

8. Centre for Communicable Diseases and Infection Control. A summary of the Pan-Canadian framework on sexually-transmitted and blood-borne infections. Can Commun Dis Rep 2018;44(7-8):179-81. DOI PubMed

9. Public Health Agency of Canada. Accelerating Our Response: Government of Canada Five-Year Action Plan on Sexually Transmitted and Blood-Borne Infections. Ottawa (ON): PHAC; 2019 July. https://www.canada.ca/en/ public-health/services/reports-publications/accelerating-ou r-response-five-year-action-plan-sexually-transmitted-bloo d-borne-infections.html

10. Public Health Agency of Canada. Harm Reduction Fund: Preventing transmission of HIV and hepatitis $\mathrm{C}$ from sharing drug injection and inhalation equipment. Ottawa, ON: PHAC; 2019. https://www.canada.ca/en/public-health/ services/funding-opportunities/harm-reduction-fund.html

11. Public Health Agency of Canada. HIV and Hepatitis C Community Action Fund. Ottawa, ON: PHAC; 2019. https://www.canada.ca/en/public-health/services/ funding-opportunities/hiv-hepatitis-community-actio n-fund-next-steps.html

12. Truth and Reconciliation Commission of Canada. Calls to Action. 2015. http://trc.ca/assets/pdf/Calls_to_Action_ English2.pdf 